\title{
Respuesta al comentario del Dr. B. Hontanilla-Calatayud
}

\section{Alexandro AGUILERA-SALGADO}

Agradecemos al Dr. Hontanilla sus amables y constructivos comentarios acerca del trabajo que hemos realizado al lograr en nuestros pacientes la reanimación facial en ambos lados de la cara en un solo tiempo quirúrgico.

En cuanto a la selección del nervio donante, está descrito el uso de diversos nervios cercanos, logrando distintos grados de fuerza y de espontaneidad. El Dr. David Chuang describe las características que debe tener un nervio motor ideal para inervar el músculo libre utilizado en reanimación facial: nervio cercano que no requiera injerto nervioso; nervio fuerte que otorgue inervación adecuada; tiempo de rehabilitación corto; mínimas morbilidades; potencial de lograr sonrisa espontánea; y aplicación universal en diversas situaciones. ${ }^{(1)}$

Como mencionamos, en nuestra práctica diaria es rutinaria la selección del nervio maseterino como primera opción en los pacientes en quienes está disponible. En aquellos en los que está afectado, optamos por utilizar el nervio espinal por diversas razones: no necesitamos injerto nervioso; fácil disección; por la edad de los pacientes (4 y 6 años) la plasticidad cerebral permite adaptabilidad en la representación cortical, logrando movimientos espontáneos; nervio fuerte que permite reinervación adecuada; produce mínima morbilidad en el sitio donador; y el tiempo de rehabilitación es corto. No consideramos el uso del nervio hipogloso debido a que, al tratarse de una reanimación facial bilateral, la morbilidad en el sitio donador puede ser muy importante, pudiendo ocasionar dificultad para el lenguaje o la deglución. En caso de utilizar un porcentaje menor del nervio para evitar estas complicaciones potenciales $(40 \%)$, consideramos que la fuerza de reinervación para lograr una contracción fuerte del músculo trasplantado será menor, con resultados menos favorables.
El uso del nervio espinal está descrito por diversos autores con resultados excelentes, como Chuang y Terzis, logrando fuerzas de contracción completas y espontáneas, tal y como hemos logrado replicar en nuestros casos. ${ }^{(1)}$

De igual forma, en nuestra práctica diaria realizamos las coaptaciones nerviosas con puntos simples de nylon 10-0 y posteriormente gel de fibrina. Se han publicado en la literatura diversos trabajos en los que no existe diferencia significativa en cuanto al uso de sutura o pegamento, siempre y cuando se logre una coaptación eficiente, sin tensión y con buen afrontamiento entre ambos cabos de los nervios, por lo que no consideramos que nuestra técnica de coaptación haya influido en nuestros resultados. ${ }^{(2)}$ En los videos que, a petición del Dr. Hontanilla adjuntamos y que están disponibles en la edición electrónica de la revista, la contracción se puede apreciar adecuadamente. La paciente a la cual hace referencia es adulta y en ella utilizamos como donante el nervio maseterino.

Continuamos trabajando en estos casos y, más adelante, compartiremos la evolución de nuestros pacientes con un seguimiento a largo plazo.

Bibliografía

1. Chuang DC. One-Stage Procedure Using Spinal Accessory Nerve (XI)-Innervated Free Muscle for Facial Paralysis Reconstruction. Plast Reconstr Surg. 2013; 132 (1): 117-129.

2. Sameem M. A Systematic Review on the Use of Fibrin Glue for Peripheral Nerve Repair. Plast. Reconstr. Surg. 2011, 127: 2381-2390.

Video complementario al artículo en: www.ciplaslatin.com 